Article

\title{
The Multi-Aspect Criterion in the PMADM Outline and Its Possible Application to Sustainability Assessment
}

\author{
Sarfaraz Hashemkhani Zolfani ${ }^{1}$, Edmundas Kazimieras Zavadskas ${ }^{2}$ (), Payam Khazaelpour ${ }^{3}$ \\ and Fausto Cavallaro $4, *$ (D) \\ 1 School of Engineering, Catholic University of the North, Larrondo 1281, Coquimbo, Chile; \\ sa.hashemkhani@gmail.com \\ 2 Institute of Sustainable Construction, Faculty of Civil Engineering, Vilnius Gediminas Technical University, \\ Sauletekis ave. 11, LT-10223 Vilnius, Lithuania; edmundas.zavadskas@vgtu.lt \\ 3 Department of Mathematics and Statistics, Curtin University, Kent U1987, Perth, Australia; \\ payam.khazaelpour@gmail.com \\ 4 Department of Economics, University of Molise, Via De Sanctis, 86100 Campobasso, Italy \\ * Correspondence: cavallaro@unimol.it
}

Received: 26 September 2018; Accepted: 5 November 2018; Published: 27 November 2018

\begin{abstract}
Over the past few centuries, the process of decision-making has become more complicated in different respects. Since the initial phase of Multiple Criteria Decision Making (MCDM) around fifty years ago, Multiple Attribute Decision Making (MADM) has continued developing over the years as a sub-concept of MCDM. Noticeably, the importance of the decision-making process is increasingly expanding to such an extent that it necessarily blends into the undeniable processes of MADM actual models. Novel methods with different perspectives have been introduced considering the dynamic MADM concepts of time and future in classical frameworks; however, they do not overcome challenges in practice. Recently, Prospective MADM (PMADM) as a specific approach has presented future-oriented models using already known approaches of MCDM, and it has innovative items which show barriers of classic model of MADM. However, PMADM practically needs more conceptual bases to illustrate and plan the future of real decision-making problems. The Multi-Aspect Criterion is a new concept in mapping the future of the PMADM outline. In this regard, two examples of sustainability will be analyzed, and different requirements and aspects associated with PMADM will be discussed in this study. This new approach can support the PMADM outline in more detail and deal with a decision-making structure that can be considered as novel to industry experts.
\end{abstract}

Keywords: Multiple Criteria Decision Making (MCDM); Multiple Attribute Decision Making (MADM); Prospective Multiple Attribute Decision Making (PMADM); Multi-Aspect Criterion; Futures Studies; future; sustainability

\section{Introduction}

Futures Studies taken as a field can be described from either a multi-disciplinary or an interdisciplinary perspective. During the last few decades, new multi-disciplinary topics have developed as either new fields or sub-fields, although they are usually categorized in both new fields and sub-fields together. Multiple Criteria Decision Making (MCDM) has kept developing over the past five decades in different aspects of operation research and applied mathematics as a sub-field. Similarly, on account of the progress in this area of knowledge, two specific international journals, namely, the Journal of Multi-Criteria Decision Analysis (Wiley) and the International Journal of Multi-Criteria Decision Making (Inderscience) have been launched and published, and they have caused this area to 
be thought of as either multi-disciplinary or interdisciplinary today. Furthermore, both Futures Studies and Multiple Criteria Decision Making (MCDM) altogether should be independent enough to offer a unified research field of interest through which future decisions will become controllable and navigable using the research field of joint MCDM and Futures Studies. Conceptually, navigable research of joint MCDM/Futures Studies aims for long-term achievements; accordingly, set goals at the present time can be carried out for future achievements, e.g., where "MADM-based scenarios" are applied for developing goals aimed at achieving success. Furthermore, making use of "MADM-based scenarios" as a long-term foresight method is suggested considering that its set goal might fail while meeting specified requirements to use "MADM-based-scenarios" towards a long-term success. The future asks special questions that normal activities will not be able to answer and that require pre-planning.

Recently, Futures Studies and MCDM have linked their structures and applications. MCDM, specifically Multiple Attribute Decision Making (MADM), has developed in several innovative ways to blend Futures Studies into its structure, adding more qualitative space, while Futures Studies require more quantitative items and space to maintain the established link. Accordingly, a decision-making process that appears complicated will have to deal with tougher situations regarding Futures Studies, in which a combination of either new fields or sub-fields will take a new category of both Futures Studies and MCDM into account simultaneously.

Recently, new paradigms and perspectives have been added to the MCDM field including Dynamic MCDM (DMADM) and Prospective Multiple Attribute Decision Making (PMADM), which are related to both decision-making and the future. Although DMADM accounts for timebased dynamics, and MADM appears to have the capability of future prediction in long-term decision-making, it fails to account for vague and unpredictable future happenings. Given the fact that future decision-making is vital in both short-term and long-term approaches, communities are consistently trying to account for the future in their decision-making to manage the world. PMADM, as the latest perspective that takes the future of MADM challenges into an account, seems useful for making reliable decisions. However, PMADM is still a broad concept, which should be developed more in different aspects and dimensions.

An ongoing challenge for current researchers in PMADM is to control probable changes through forecasting, thereby allowing one to answer the question of how to achieve a long-term target or aim. Different activities, scenarios, and developments cause many differentiations in which real challenges are defined based on long-term issues. Generally, criteria and their definitions over the years can change greatly. Responding to and solving the challenges of long-term issues is a new contribution of the PMADM space and framework, which happens to be the most important part of our research question and which has received much attention. Consequently, the Multi-Aspect Criterion as a new item with a novel perspective, which takes account of the future in the MADM model, consists of a new part of the PMADM structure. This research will show how reliably the Multi-Aspect Criterion can perform, define its framework, and eventually explain all the multidisciplinary aspects and dimensions of this item in detail.

\section{Prospective Multiple Attribute Decision Making (PMADM)}

Previously, MADM aimed to study decisions in a fixed and stable situation. In the past decade, dynamic MADM has started developing to merge with time as an item in decision-making processes. However, the special futures perspective, which is issued with an item, remains underdeveloped. For instance, explorative and descriptive perspectives about the future do not occupy any position in the process of decision making, specifically when a decision is made with unfixed information about the future. In fact, in under-complicated decision-making circumstances, new items that are far from classic items, namely, criteria, alternatives, and weights of criteria, will be needed. Subsequently, PMADM is a specialized approach for considering the future in MADM models, which is capable of meeting the requirements of both Futures Studies and MADM fields concurrently.

The possibilities and different occurrences of frameworks are related to scenarios reviewed by PMADM. Limiters and boosters are assessed as two new items of perspective future, and their 
applications are also described and investigated. Conceptually, limiters and boosters in different future situations (and scenarios) cause different values and evaluations for alternatives given the selection of criteria towards evaluation purposes. However, in application, limiters are more common than boosters because they can be used when something occurs beyond evaluations and estimates. There is also a realistic assessment for accepting different occurrences of the future, for which a normal situation is defined to be the closest expectation as a basis for the future of a scenario [1].

PMADM needs be developed because of Futures Studies' requirements for decision-making purposes. One of the main challenges can be ability of PMADM in defining criteria based on future needs. Furthermore, this research focuses on this topic and will emphasize how criteria, their essences, and their definitions can change in different perspectives, frameworks, and structures in general. Additionally, a new item called the Multi-Aspect Criterion is introduced within the PMADM approach to meet Futures Studies' requirements for the decision-making process.

\section{Previous Contributions in MADM}

In recent decades, MADM has developed into many different aspects and dimensions. However, according to general perspective in decision science, there are two core categories of MADM as follows:

1. Contributions in methods

2. Contributions in time consideration

\subsection{Contributions in Methods}

Table 1 presents different MADM methods and different points of view ranging from 1968 to today.

Table 1. Common and newest Multiple Attribute Decision Making (MADM) methods.

\begin{tabular}{|c|c|c|c|}
\hline & Abbreviation & Full Name & Reference \\
\hline 1 & SAW & Simple Additive Weighting & MacCrimon [2] \\
\hline 2 & ELECTRE & $\begin{array}{l}\text { Elimination Et Choix Traduisant la Realité (Elimination } \\
\text { and Choice Expressing Reality) }\end{array}$ & Roy [3] \\
\hline 3 & AHP & Analytic Hierarchy Process & Saaty [4] \\
\hline 4 & TOPSIS & $\begin{array}{c}\text { Technique for Order } \\
\text { Preference by Similarity to Ideal Solution }\end{array}$ & Hwang \& Yoon [5] \\
\hline 5 & PROMETHEE & $\begin{array}{l}\text { Preference Ranking Organization Method for } \\
\text { Enrichment of Evaluations }\end{array}$ & Brans [6]; Brans et al. [7] \\
\hline 6 & TODIM & Interactive and Multi-Criteria Decision Making & Gomes and Lima [8] \\
\hline 7 & ANP & Analytic Network Process & Saaty $[9,10]$ \\
\hline 8 & COPRAS & $\begin{array}{l}\text { Complex } \\
\text { Proportional Assessment }\end{array}$ & Zavadskas \& Kaklauskas [11] \\
\hline 9 & VIKOR & $\begin{array}{l}\text { VIseKriterijumska Optimizacija I Kompromisno Resenje } \\
\text { (Multi-criteria Optimization and Compromise Solution) }\end{array}$ & Opricovic [12] \\
\hline 10 & ARAS & Additive Ratio Assessment & Zavadskas et al. [13] \\
\hline 11 & SWARA & Step-Wise Weight Assessment Ratio Analysis & Kersuliene et al. [14] \\
\hline 12 & FARE & Factor Relationship & Ginevicius [15] \\
\hline 13 & WASPAS & Weighted Aggregated Sum Product Assessment & Zavadskas et al. [16] \\
\hline 14 & KEMIRA & Kemeny Median Indicator Ranks Accordance & Krylovas et al. [17] \\
\hline 15 & BWM & Best-Worst Method & Rezaei [18] \\
\hline 16 & EDAS & Evaluation Based on Distance from Average Solution & Keshavarz Ghorabaee et al. [19] \\
\hline 17 & CODAS & A New, Combinative Distance-Based Assessment & Keshavarz Ghorabaee et al. [20] \\
\hline 18 & SECA & Simultaneous Evaluation of Criteria and Alternatives & Keshavarz Ghorabaee et al. [21] \\
\hline 19 & CoCoSo & Combined Compromise Solution & Yazdani et al. [22] \\
\hline
\end{tabular}


Other less-prevalent MADM methods not shown in Table 1 are presented below:

- Organization, Management Et Synthese De Donnees Relationnelles (French), or organization, storage, and summarizing of relational data in English (ORESTE) [25].

- Treatment of the Alternatives according to the Importance of Criteria (TACTIC) [26].

- Analytic Centre UTilité Additive (ACUTA) [27].

- MUlticriteria Satisfaction Analysis (MUSA) [28].

\subsection{Contributions in Time Consideration}

In this section, contributions will be discussed in two main sections, detailing direct and indirect approaches.

\subsubsection{Direct Contributions}

Since 1988, some research articles have considered time generally and directly as an effective index in the MADM framework [29-43]. Explanations of time contribution differed in these research articles. However, in these studies time plays a key role in MADM models. In the changing process of MCDM methods, Dynamic MADM (DMADM) has developed in parallel with the methods and additional logic of fuzzy and grey. Figure 1 graphically divides these into three categories in terms of time considerations.

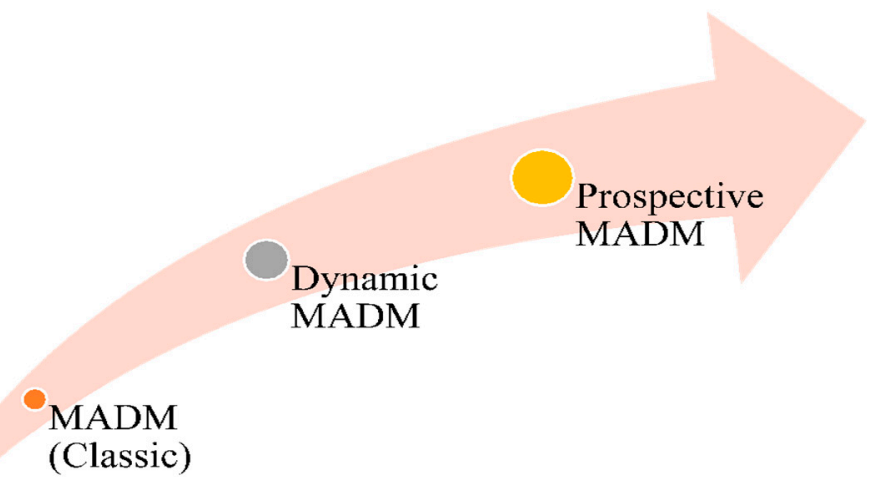

Figure 1. MADM evolution in time consideration (Direct approach).

\subsubsection{Indirect Contribution}

The main idea in this section is described in two sections as follows:

1. Scenarios based on MCDM (MADM)

In this combination, MCDM (mostly MADM) methods are applied in evaluating scenarios for future policymaking. In this state, scenarios are taken as alternatives, and criteria are defined in each case/topic for the purpose of evaluating and ranking the alternatives (scenarios) [44-56]. In fact, MCDM methods are applied as evaluators of future perspective scenarios, in which, mostly, scenario planners and future thinkers are contributors. These multidisciplinary research fields have been developed for different perspectives and viewpoints.

2. MADM-based scenarios

This approach differs greatly from the "scenarios based on MADM", in which decision making is key. According to "MADM based Scenarios", Futures Studies and scenarios are the core and decisionmaking models and methods support the evaluation of all scenarios, separately [57]. This approach aims to illustrate and evaluate future states in a more appreciable space where different probable future 
scenarios can be included, and reliable signs/points can be achieved in a more general sense [58]. Briefly, the future is managed by having different probable outcomes that lead to packed evaluations for future generations. Having achieved probable outcomes in different future scenarios, the most vital key results with respect to the future are finally discussed.

\section{Futures Studies and PMADM}

"Futures Studies" as a major and field has been accepted within academia, though it still needs to mature, taking a revolutionary path to development [59]. The concept of futures can be divided into four distinct groups, categorized as follows [60]:

1. Possible Futures

2. Plausible Futures

3. Probable Futures

4. Preferable Futures

PMADM is designed to contain future group(s) in the following areas:

1. Theory,

2. Practice; and

3. The logic on which a decision is based either to solve or create a challenge.

Afterwards, each four concepts of the future four items are explained carefully as to which group of future considerations we will face, either individually or combined.

Foresight is generally a systematic effort with a long-term perspective in different areas such as science, technology, economic, environment, and society. Significantly, it seeks to identify newfound technologies and their relations to economic investments and social profitability. Foresight is readiness for the future giving rise to value while making use of available sources as best possible [61,62].

Futures Studies is about the future and does not necessarily need to be practical with strategic plans [63]. Having included differences between prediction and Futures Studies, the vision for Futures Studies seeks to be more long-term than prediction. Scientifically, the science of prediction, which noticeably emphasizes the short-term future, began roughly five years ago. Studies of long-term changes only began to flourish between ten and fifty years ago. Definitely, prediction does not deliver all future benefits. Futures Studies considers different probable and predictable distant future outcomes, giving rise to the significance of Futures Studies. Moreover, methods are strictly quantitative in prediction, while Futures Studies uses both qualitative and quantitative methods of calculation [64].

Considering applicability of Futures Studies and foresight science, PMADM can be defined for both approaches by how it can discover the future and possibly manage it.

Different methods of Futures Studies can mostly be categorized based on explorative and descriptive approaches $[65,66]$. PMADM covers both an explorative and a descriptive decision, meeting the needs of policymakers. In the first model of PMADM, limiters and boosters can take both perspectives, explaining a stable and expectable situation of the future. Additionally, an alternative is accounted for to specifically concede to the descriptive perspective in this model. However, limiters and boosters enjoy a more explorative perspective, considering special futures of different scenarios. Applicably, splitting decision types in two, the descriptive approach mostly points out how the future needs to be constructively controlled, managed, and built up, taking into account both the positive and negative effects of sub-decisions. While explorative decisions seek more to lead decision makers towards a pre-considered purpose that satisfies their requirements, they offer a detailed look at the future as well. Descriptive decisions require attaching to a predetermined set of future goals to purposely reach the social desires of a community. Meanwhile, explorative decisions have already investigated possible future outcomes resulting in four main types of future. 


\section{New Hybrid/Mixed Criteria Facing the Future}

The future is intertwined with vagueness and ambiguity in many aspects and dimensions. Due to the emergence of dynamic and prospective MADM models, new items and approaches must be combined with classical MADM, and accordingly they must be reviewed again. A major part of each MADM model and method is criteria. In fact, definition of a criterion can vary according to the classical perspective of MADM structure and employ an approach in each time period due to its needs and expectations will be considerable. It is important to understand exactly what our expectations from a criterion will be in the future. This could be answered by either justification or a revised version of criterion/criteria. In the latter question, it is essential to evaluate and understand its possibilities. Subsequently, different topics should be considered when presenting criteria for a certain "time period" or "exact time" in the future.

Criteria, which are studied in the same manner as alternatives, will likely change due to new possibilities. The definition of a decision and a decision space both play a key role in combining the prospective model with a "time period" and an "exact time". Additionally, future approaches acknowledge a long-term influence over the new possibilities. Both explorative and descriptive approaches diverge into distinct directions, leading to different decision frameworks. The definition and application of criteria in this type of decision structure within MADM models appears relatively complicated, specialized, and distinguished. Conceptually, the first direct connection of MADM models and the future is made through future approaches and perspectives. The two main approaches in the field, explorative and descriptive, are fundamental to Futures Studies. Many Futures Studies methodologies, like "Scenario planning" and "Backcasting", which both perform well, make use of the two approaches. Accordingly, connections made between MADM structures and Futures Studies should present a better definition for criteria in the future.

Foresight is taken into account in both of the mentioned future approaches of MADM structure, in which a defined future plan takes into account both what is desired and what occurs in reality. In dealing with the details of a MADM model, criteria are directed through the same requirements as the general structure of MADM, and it is essentially required to include them. Moreover, each criterion provides enough flexibility to support future requirements in MADM models. Conceivably, possible Futures, plausible Futures, probable Futures, and preferable Futures could develop a prospective MADM, which could allow for dynamism using different items and incorporated criteria. Noticeably, new items included in MADM models seal the gap between imagination and reality. Therefore, a criterion and its position in the big picture of decision making are undeniably significant and have attracted much scientific attention to Futures Studies thus far.

\section{Multi-Aspect Criterion}

A Multi-Aspect Criterion is an indicator in prospective MADM, which introduces a novel and important factor to this subject. The image of the future is described in a new space as a new criterion, called a Multi-Aspect Criterion, which must be clearly defined. The idea of a Multi-Aspect Criterion parallels the uncertainty of a model when a difference arises between prediction and forecasting over a long-term period. When planning a scenario, possible outcomes of the future are investigated and then collected in a new featured criterion, called Multi-Aspect Criterion. Through this process, the known concepts of present time are merged with a new concept of the imagined future. These concepts have specific definitions, as required by the definition of Multi-Aspect Criterion. This drives a new meaning of the future, combining the current known definition of criteria and aiming for the establishment of Multi-Aspect Criterion. The concept of uncertainty, often perceived as confusing, defines an opportunity. In fact, humanity wonders what the future will cause it to encounter in situations in which tolerance is taken into account. Imaginably, this tolerance includes many thoughts and ideas about possible outcomes that a Multi-Aspect Criterion must take into account. Therefore, two primary conditions necessary to present a new Multi-Aspect Criterion are required to: 
- have a certain definition

- imagine the future

A Multi-Aspect Criterion is categorized in the two following groups:

1. Hybrid criteria as a new criterion

According to the future needs and scenarios, some criteria are considered as a package that is driven by a new criterion. Although hybrid criteria are introduced as a package, the current situation can be justified by and classified as different research areas. Uncertainties are included in PMADM models, creating a significant challenge among many others, where definitions such as criteria and alternatives are required. Hybrid criteria aid in comprising scenarios in the classic MADM models if they are effectively proven. Specifically, the term "Hybrid criteria" does not mean a package that is necessarily presented. However, the term could describe a general concept in a situation in which a known perspective seems too conceptually distant at the present time, knowing the fact that it could possibly be developed based on related requirements. Moreover, hybrid criteria compared with other criteria types are more realistic, as they include uncertainty within modeling processes, making use of varying MCDM methods simultaneously to establish four different groups as shown in Figure 2.

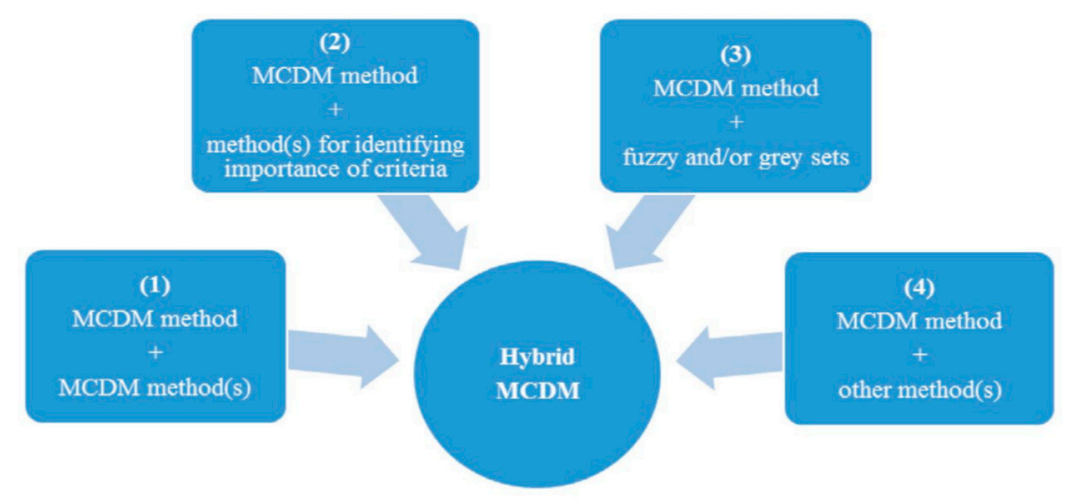

Figure 2. Composition modes of Hybrid Multiple Criteria Decision Making (HMCDM), using hybrid criteria as a criterion.

Criteria of common MADM methods are relatively independent and hierarchical. While hybrid criteria link interdependent and sub-structured criteria, uncertainties can use fuzzy/gray numbers to achieve a realistic decision-making process. Secondly, hybrid criteria combined as a new criterion are brought to a higher level of criteria structure at which the future comes with aspirations. Also, the procedure of ranking achieved by MADM method(s) will be substituted for performance improvement as a new hybrid criterion.

2. A lately defined concept for the other criteria as a criterion

The criteria that have different aspects with unique parts and definitions are named accordingly. In other words, some features and definitions will be imagined and considered as common features or definitions in the future when solving a decision-making challenge. This is more complicated than their current imagination and background. Conceptually, definition of a criterion needs to be presented in a novel manner. In fact, a number of criteria outline the best way to describe the situation in the future, given that the definition of a new perspective in presenting criteria can maintain the importance of criteria in terms of quantity, status, and position. To compare briefly, the main difference between these two approaches is the creation of a new definition and expression of the new criterion as opposed to the common definitions of criteria, known as a new mixed/hybrid criterion. Due to the future vagueness and decision-making process variabilities, a proper and accurate decision fails to achieve, specifically when hybrid criteria are defined and modeled within a decision-making process. Hypothetically, proper decision making may be similar to what is already planned for the near or 
distant future following long-term forecasting calculation. However, humanity must be reasonably sure of future events and unexpected happenings, which either positively or negatively affect final decision-making outcomes. This leads to future dimensions in terms of overcoming the vagueness and blurriness of the future while attempting to make a decision. As a result, a priority necessarily emerges that is connected with the set goal of the investigating criterion as follows:

1. Evaluation reliability of hybrid criterion

2. Approachability and tolerable costs

3. Acceptability to the sponsor (expert)

First and foremost, reliability of criterion evaluation is of great significance when it comes to the constitution of a hybrid criterion. In fact, a hybrid criterion needs to be set up for crude practicality before stepping towards hybridization. Afterward, other outlooks of the future accompany it and must be incorporated into through the rest of the calculation. Secondly, the approachability of the criterion requires further investigation in terms of its future occurrence, in order to outline the costs of implementation. Lastly, experts' thoughts are included as if the criterion has passed through a process of creditability, for which the last step is lodged through experts' / sponsors' ideas. This step is commonly known as a questionnaire-filling process in which experts are completely in charge of weighting pre-determined criteria to further investigate the next stages of the decision-making process.

\section{How to Consider Multi-Aspect Criterion in Practice}

One of the most vital topics in applying Multi-Aspect Criterion is weighting approach. Criteria weighting is a crucial challenge that presents three probable important approaches as follows:

1. Multi-aspect weighting

This is directly applied for Multi-Aspect Criterion. It is also capable of using fuzzy and grey numbers due to the application of flexibly different dimensions, which are provided for each MultiAspect Criterion and for which each is assigned a separate weighting logic.

2. Time-based weighting

This includes dynamic, periodic, and constant weighting. The main object of time-based weighting is to demonstrate well-defined time periods. Moreover, it includes a multi-step approach while weighting. The time-based weighting process in this category is not necessarily fixed and might face different periods of future change, although the changes are unclear on occurrence of events.

3. Approach-based weighting

Approach-based weighting could be either explorative or descriptive, as previously defined. However, when it is descriptive structure it is more useful. Also, sensitive weighting is applicable, supported by feedbacks and justification.

The hybrid approach is imaginable according to the triple approaches (three ways).

\section{Multi-Aspect Criterion Based on Examples of Sustainability}

Having described the two approaches, a Multi-Aspect Criterion is introduced in practice. Hypothetically exemplified, criteria are presented to define a suitable and probable future. This is only defined by reasonable logic when a trend seems measurable through the time periods. The following sections show why this approach is an integral part of MADM models. As MADM models and methods are applicable and important in the field of sustainability, it is clear that these new approaches apply to new perspectives in sustainability issues [67-70].

Clearly explained, a Multi-Aspect Criterion is not itself imaginable at the present time; however, it will be in the long-term. When it comes to a Multi-Aspect Criterion, each separate concept of the present time is merged with the future, in which new concepts of meaninglessness at the present become 
meaningful in the future. This is shown in the example below, called Exergy. Finally, the Multi-Aspect Criterion currently defined undergoes trend analysis for better scenario planning and implementation of social desires in a community.

\subsection{First Trend}

The first trend explains the concept of sustainability as either a criterion or criteria. Previously, economic, social, and environmental issues were used as different criteria, each of which could be combined into many possible groupings of criteria. Although today the triple aspects of sustainability are vital to MADM modeling, in main policies sustainable development or sustainability (as it shown in Figure 3) usually develop different questions, challenges, and problems from varying scientific backgrounds [71,72].

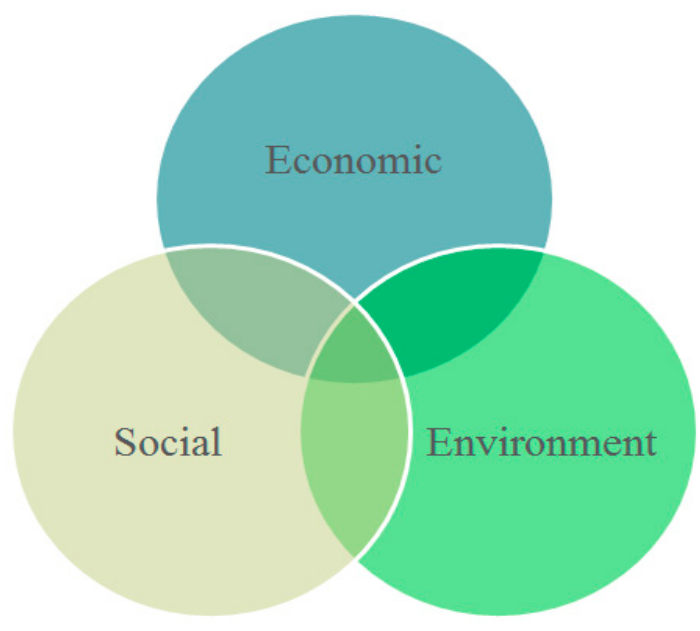

Figure 3. Sustainability framework.

Recently, futures sustainability has become a new framework for evaluating the main policies, or at least it can withstand evaluation. Publicly, policies of strategic foresight, very long-term planning, and future sustainability (as shown in Figure 4) are seen as effective and important parts of evaluations. Tonn [73] developed this new approach in practice, which made use of the differences and changes in each section of the sustainability framework to develop in a strategic foresight plan. Three main principles defined for futures sustainability and emphasized by some primary approaches are undoubtedly necessary for the future and humankind. Currently, futures sustainability is imagined as an umbrella for the concept of sustainability, in which the future economy, environment, and society position introduce alternative countries as the leaders of the world, in terms of the long-term forecast. Moreover, the phrase "futures sustainability" benefits from the Economist Intelligent Unit (EIU) and describes the fifty-year forecast to 2050, establishing a trend of future foresight.

This new approach is only one important criterion that must be assumed in policies and projects in critical future decisions. Undoubtedly, different concepts and approaches could be imagined in this phase and are dynamically defined in the big picture, having more depth within their structures. Eventually, futures sustainability is presented as a new approach that covers the triple sustainability concepts and plays the role of a final goal to seek other approaches and trends simultaneously. Additionally, other trends and approaches can be developed flexibly either in parallel or separately. 


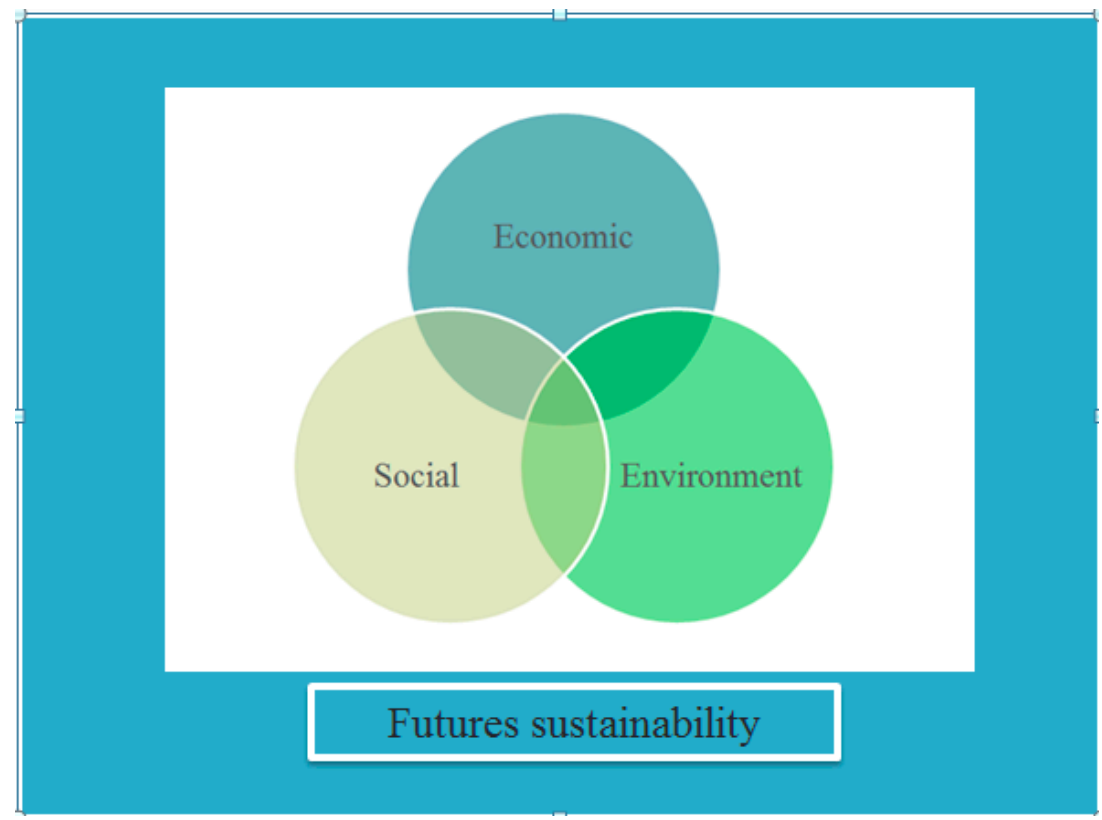

Figure 4. Futures sustainability approach.

\subsection{Second Trend}

The second trend basically abides by the previous trend, demonstrating how the world has changed. Sustainability, shown graphically below, is a new approach. It seeks to better envision the future and evolve itself as better visions are reached in the future.

Another trend (method) to consider is Exergy, which combines and grows energy, environment, and sustainable development in a common framework [74].

Obviously, sustainable development (sustainability) is simultaneously a vital but not a core part of this approach. The environment is included due to its importance in this approach and helps create a balanced situation in developing phases. Lastly, energy is introduced as a core item in this case, in equal proportion to the other items of the Exergy balance.

The equilibrium is shown in Figure 5.

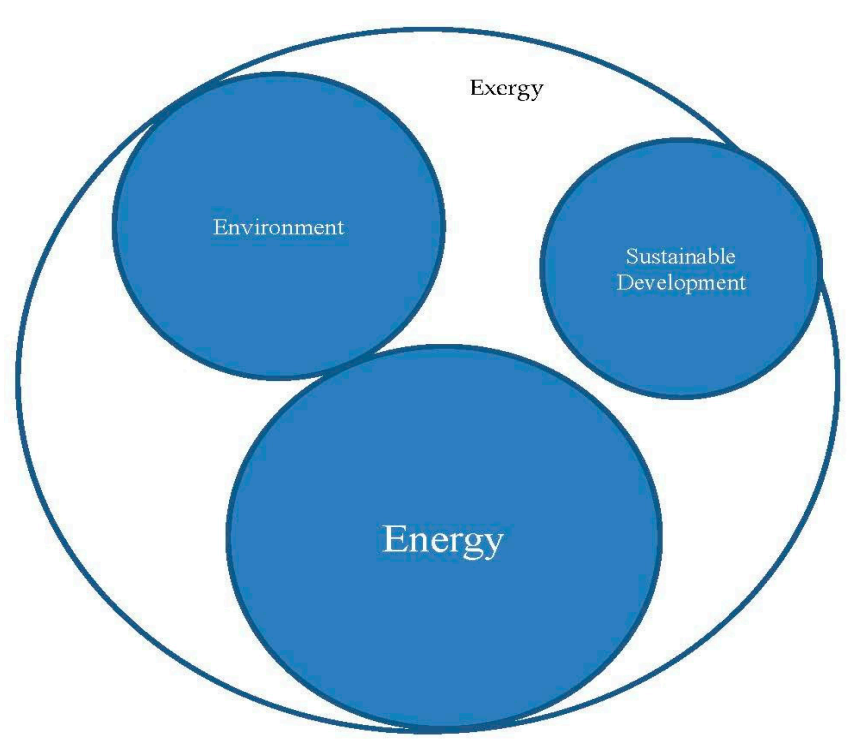

Figure 5. Exergy and its approach. 
These are not the only trends and cases in critical policies presented as criteria. Actually, these trends are not only predictable and readable in literature but are also capable of being developed with both expert panels' ideas and explorative/descriptive methodologies. Moreover, perspectives can potentially accompany them in both theoretical and practical aspects.

Policymakers, pioneers of the markets; regulatory bodies like the United Nations (UN), the World Trade Organization (WTO), and other similar organizations; leading universities (both international and local); and all other strong authorities can shape the world and the future. These powers can and do present new concepts for different societies. As the world progresses, their role will expand. Therefore, policymakers of a community, society, or country can use this new approach in their plans for building a better future, although this approach still needs to be developed and implemented. However, due to its unfamiliarity and novelty, it is not possible to demonstrate the advantages and positive contributions of this approach. Furthermore, to obtain reliable outputs we need to manage each aspect, which can be time-consuming, as only time shapes the future.

\section{Discussion}

PMADM presents a new vision, considering the future of classic MADM models. Although it seems like a simple approach, the depth of the main concept identifies the type of structure that PMADM model undoubtedly faces. Classic items conceptually need new perspectives and dimensions, and, fortunately, novel and distinct items can be easily included by this new approach. Criteria, weights of criteria, and alternatives form the basis of each classic MADM model, while in the primary PMADM model some new visions for alternatives are analyzed and presented.

Criteria as one of the most important parts of each MADM model need new attention and evolutionary paradigms. Different dimensions are imaginably defined to create a new structure of the criteria as part of each PMADM model. Multi-Aspect Criterion introduces two basic parts identified for the new concept as follows: hybrid criteria as a new criterion, and a newly defined concept for the criteria as a criterion. Identifiably, these newly introduced concepts shed light on the atmosphere of the future in practice.

Facing the challenges, problems, and shortcomings that are critical for each community, society, and stakeholders depends on either future occurrences or the future course of actions in the real world. Based on the two mentioned standpoints, an appropriate space is planned and a suitable aspect for Multi-Aspect Criterion can be selected as an example of a PMADM model for the future. Justifiably, new reasons are taken into consideration, because future requirements emerge flexibly with dynamics and multi-dimensions. Research on this new concept will certainly expand more in the future, according to challenges and problems that arise.

Definitions and interpretations of many concepts are evolving, creating new methods of criteria presentation, which are evaluated according to the present pace of change. Attempts to scale the pace of these changes are assessed by how much the approach can be changed, developed, and expanded in the future. Criteria together with their definitions, interpretations, and hermeneutic approaches must be expanded due to a simple explorative and descriptive perspective in facing unknowns of the future. However, the future is no longer unknown, as general policy makers know our future needs, limitations, expectations, and probable challenges. Accordingly, societies should identify their probable and perceptible solutions for the future.

Finally, Multi-Aspect Criterion is a new bridge to a realizable future, in which classic models are not strong enough to meet our future needs and expectations. For this reason, developing the essential and fundamental parts of a reliable decision is necessary., according to the requirements and special structures of a PMADM model in future-oriented decision challenges.

\section{Conclusions}

Unlike other novel approaches, PMADM still needs to be expanded and developed in a professional and logical manner. It still needs to advance classical components, namely criteria, 
weights, alternatives, and various new aspects and dimensions. These new parts and items need definitions, which are dealt with in an in-depth manner using different concepts and frameworks. Individually, criteria play a key role in decision-making processes and in the comprehensive evaluation of alternatives. They and their importance in future-oriented cases were central to this study, in which a new concept can explain a core focus in the future.

The "Multi-Aspect Criterion", introduced as a new concept regarding sustainable dimensions, is considered and interpreted. Illustratively, this criterion should have certain definitions and be imaginable in the future, although it is not completely understandable at present. This concept performs based on the situation in which both sides of explorative/descriptive topics of the future are presented, for which PMADM modeling appears as a professional activity of doable and understandable performances. However, most national and international foresight programs and plans merely imagine one-sided criteria, in reality due to the fast progress of our world.

The main point for future consideration of the Multi-Aspect Criterion is that it can be defined as a hybrid criterion that performs in a new structure as a new criterion. This is a newly defined concept as a criterion that is not an issue today but will become imaginable as a vital point in unknown events in the future. These above-mentioned criteria need to be weighted differently. A newly defined criterion necessitates complicated processing methods for weighting, which are presented as follows: multi-aspect weighting, time-based weighting, and approach-based weighting. Researchers and policymakers make their own decisions on the weighting after choosing one.

Consequently, a new vision is designed by but not limited to this framework in which new contributions are predicted for PMADM modeling. Having reasoned about criteria and their relation to the alternatives, other factors can shape this relation dynamically and prospectively to anticipate future events through a flexible modeling process. Finally, definition processes in this new concept are another potential niche that will likely attract research attention, supposing a reality-based perspective of the future.

Author Contributions: Main idea, conceptualization, hypothesizing, literature review, writing-original draft by H.Z.S.; Supervision, functionality of the main idea and validating the idea based on current literature by Z.E.K.; Framework, improving and editing by K.P.; Writing—review \& editing draft by C.F.

Funding: This research received no external funding.

Conflicts of Interest: The authors declare no conflict of interest.

\section{References}

1. Hashemkhani Zolfani, S.; Maknoon, R.; Zavadskas, E.K. An introduction to Prospective Multiple Attributes Decision Making (PMADM). Technol. Econ. Dev. Econ. 2016, 22, 309-326. [CrossRef]

2. McCrimon, K.R. Decision Marking among Multiple Attribute Alternatives: A Survey and Consolidated Approach; RAND Memorandum, RM-4823-ARPA; The Rand Corporation: Santa Monica, CA, USA, 1968.

3. Roy, B. Classement et choix en presence de point de vue multiples: Le methode ELECTRE. Revue Francaise d'Informatique et de Recherche Operationnelle (RIRO) 1968, 8, 57-75.

4. Saaty, T.L. The Analytical Hierarchy Process; McGraw-Hill: New York, NY, USA, 1980.

5. Hwang, C.L.; Yoon, K. Multiple Attribute Decision Making: A State of the Art Survey; Lecture Notes in Economics and Mathematical Systems; Springer: Berlin, Germany, 1981; Volume 186.

6. Brans, J.P. L'ingénierie de la décision: Élaboration d'instruments d'aide à la décision. La méthode PROMETHEE; Presses de l'Université Laval: Québec, Canada, 1982.

7. Brans, J.P.; Mareschal, B.; Vincke, P. PROMETHEE: A new family of outranking methods in multicriteria analysis. In Operational Research '84 IFORS 84, 6-10 August 1984, Washington, D.C., USA; Brans, J.P., Ed.; Elsevier Science Pub. Co.: Amsterdam, The Netherlands, 1984; pp. 477-490.

8. Gomes, L.F.A.M.; Lima, M.M.P.P. TODIM: Basics and application to multicriteria ranking of projects with environmental impacts. Found. Comput. Decis. Sci. 1992, 16, 113-127.

9. Saaty, T.J. Decision Making in Complex Environments, The Analytical Hierarchy Process for Decision Making with Dependence and Dependence and Feedback; RWS Publications: Pittsburgh, PA, USA, 1996. 
10. Saaty, T.L. Fundamentals of analytic network process. In Proceedings of the International Symposium on the Analytic Hierarchy Process, Kobe, Japan, 12-14 August 1999; pp. 348-379.

11. Zavadskas, E.K.; Kaklauskas, A. Determination of an efficient contractor by using the new method of multicriteria assessment. In International Symposium for "The Organisation and Management of Construction". Shaping Theory and Practice 2: Managing the Construction Project and Managing Risk; Langford, D.A., Retik, A., Eds.; CIB W: London, UK; Weinheim, Germany; New York, NY, USA; Tokyo, Japan; Melbourne, Australia; Madras, India; E and FN SPON: London, UK, 1996; Volume 65, pp. 94-104.

12. Opricovic, S. Multiple Criteria Optimization of Civil Engineering Systems; Faculty of Civil Engineering: Belgrade, Serbian, 1998.

13. Zavadskas, E.K.; Turskis, Z.; Vilutiene, T. Multiple criteria analysis of foundation instalment alternatives by applying additive ratio assessment (ARAS) method. Arch. Civ. Mech. Eng. 2010, 10, 123-141. [CrossRef]

14. Keršulienè, V.; Zavadskas, E.K.; Turskis, Z. Selection of rational dispute resolution method by applying new step-wise weight assessment ratio analysis (SWARA). J. Bus. Econ. Manag. 2010, 11, 243-258. [CrossRef]

15. Ginevicius, R. A New Determining Method for the Criteria Weights in Multi-Criteria Evaluation. Int. J. Inf. Technol. Decis. Mak. 2011, 10, 1067-1095. [CrossRef]

16. Zavadskas, E.K.; Turskis, Z.; Antucheviciene, J.; Zakarevicius, A. Optimization of weighted aggregated sum product assessment. Electron. Electr. Eng. 2012, 122, 3-6. [CrossRef]

17. Krylovas, A.; Zavadskas, E.K.; Kosareva, N.; Dadelo, S. New KEMIRA Method for Determining Criteria Priority and Weights in Solving MCDM Problem. Int. J. Inf. Technol. Decis. Mak. 2014, 13, 1119-1133. [CrossRef]

18. Rezaei, J. Best-worst multi-criteria decision-making method. Omega 2015, 53, 49-57. [CrossRef]

19. Keshavarz Ghorabaee, M.; Zavadskas, E.K.; Olfat, R.; Turskis, Z. Multi-Criteria Inventory Classification Using a New Method of Evaluation Based on Distance from Average Solution (EDAS). Informatica 2015, 26, 435-451. [CrossRef]

20. Keshavarz Ghorabaee, M.; Zavadskas, E.K.; Turskis, Z.; Antucheviciene, J. A new combinative distance-based assessment (CODAS) method for multi-criteria decision-making. Econ. Comput. Econ. Cybern. Stud. Res. 2016, 50, 25-44.

21. Keshavarz Ghorabaee, M.; Amiri, M.; Zavadskas, E.K.; Turskis, Z.; Antucheviciene, J. Simultaneous Evaluation of Criteria and Alternatives (SECA) for Multi-Criteria Decision-Making. Informatica 2018, 29, 265-280. [CrossRef]

22. Yazdani, M.; Zarate, P.; Zavadskas, E.K.; Turskis, Z. A Combined Compromise Solution (CoCoSo) method for multi-criteria decision-making problems. Manag. Decis. 2018, in press. [CrossRef]

23. Ou Yang, Y.P.; Shieh, H.M.; Leu, J.D.; Tzeng, G.H. A Novel Hybrid MCDM Model Combined with DEMATEL and ANP with Applications. Int. J. Oper. Res. 2008, 5, 160-168.

24. Liu, J.Y.; Shiue, W.; Chen, F.H.; Huang, A.T. A multiple attribute decision making approach in evaluating employee care strategies of corporate social responsibility. Manag. Decis 2018, in press. [CrossRef]

25. Roubens, M. Preference relations on actions and criteria in multi-criteria decision making. Eur. J. Oper. Res. 1982, 10, 51-55. [CrossRef]

26. Vansnick, J.C. On the problem of weights in multiple criteria decision making (the noncompensatory approach). Eur. J. Oper. Res. 1986, 24, 288-294. [CrossRef]

27. Bous, G.; Fortemps, P.; Glineur, F.; Pirlot, M. ACUTA: A novel method for eliciting additive value functions on the basis of holistic preference statements. Eur. J. Oper. Res. 2010, 206, 435-444. [CrossRef]

28. Grigoroudis, E.; Siskos, Y. Preference disaggregation for measuring and analysing customer satisfaction: The MUSA method. Eur. J. Oper. Res. 2002, 143, 148-170. [CrossRef]

29. Ozernoy, V.M. Multiple criteria decision making in the USSR: A survey. Naval Res. Logist. 1988, 35, 543-566. [CrossRef]

30. Leong, T.Y. Multiple perspective dynamic decision making. Artif. Intell. 1998, 105, 209-261. [CrossRef]

31. Salo, A.; Gustafsson, T.; Ramanathan, R. Multi-criteria methods for technology foresight. J. Forecast. 2003, 22, 235-255. [CrossRef]

32. Xu, Z.; Yager, R. Dynamic intuitionistic fuzzy multi-attribute decision making. Int. J. Approx. Reason. 2008, 48, 246-262. [CrossRef] 
33. Lou, C.; Kou, G.; Peng, Y.; Ge, X. DMCDM: A dynamic multi criteria decision making model for sovereign credit default risk evaluation. In Proceedings of the 2nd International Conference on Software Engineering and Data Mining (SEDM), Chengdu, China, 23-25 June 2010; pp. 489-494.

34. Campanella, G.; Ribeiro, R.A. A framework for dynamic multiple-criteria decision making. Decis. Support Syst. 2011, 52, 52-60. [CrossRef]

35. Trutnevyte, E.; Stauffacher, M.; Scholz, R.W. Linking stakeholder visions with resource allocation scenarios and multi-criteria assessment. Eur. J. Oper. Res. 2012, 219, 762-772. [CrossRef]

36. Arms, H.; Wiecher, M.; Kleiderman, V. Dynamic models for managing big decisions. Strategy Leadersh. 2012, 40, 39-46. [CrossRef]

37. Zhang, Z. An approach to dynamic multi-attribute decision making for choosing green supplier. J. Converg. Inf. Technol. 2012, 7, 261-269.

38. Hashemkhani Zolfani, S.; Aghdaie, M.H.; Derakhti, A.; Zavadskas, E.K.; Morshed Varzandeh, M.H. Decision making on business issues with foresight perspective; an application of new hybrid MCDM model in shopping mall locating. Expert Syst. Appl. 2013, 40, 7111-7121. [CrossRef]

39. Wang, Y.; Shi, X.; Sun, J.; Qian, W. A grey interval relational degree-based dynamic multi-attribute decision making method and its application in investment decision making. Math. Probl. Eng. 2014, 2014. [CrossRef]

40. Tadic, S.R.; Zecevic, S.M.; Krstic, M.D. Ranking of logistics system scenarios for central business district. Promet-Traffic Transp. 2014, 26, 159-167. [CrossRef]

41. Gonzalez-Prida, V.; Viveros, P.; Barbera, L.; Crespo Marquez, A. Dynamic analytic hierarchy process: AHP method adapted to a changing environment. J. Manuf. Technol. Manag. 2014, 24, 457-475. [CrossRef]

42. Ondrus, J.; Bui, T.; Pigneur, Y. A Foresight Support System Using MCDM Methods. Group Decis. Negot. 2014, 24, 333-358. [CrossRef]

43. Jassbi, J.J.; Ribeiro, R.A.; Varela, L.R. Dynamic MCDM with future knowledge for supplier selection. J. Decis. Syst. 2014, 23, 232-248. [CrossRef]

44. Supriyasilp, T.; Pongput, K.; Bonyasirikul, T. Hydropower development priority using MCDM method. Energy Policy 2009, 37, 1866-1875. [CrossRef]

45. Browne, D.; O’Regan, B.; Moles, R. Use of multi-criteria decision analysis to explore alternative domestic energy and electricity policy scenarios in an Irish city-region. Energy 2010, 35, 518-528. [CrossRef]

46. Durbach, I.; Stewart, T. A comparison of simplified value function approaches for treating uncertainty in multi-criteria decision analysis. Omega 2012, 40, 456-464. [CrossRef]

47. Petit, P.J.; Fraser, P.D. What is the best energy delivery systems for hand-held stope drilling and associated equipment in narrow-reef hard rock mines? In Proceedings of the 5 th International Platinum Conference “A Catalyst for Change", Sun City, South Africa, 17-21 September 2012; pp. 1037-1053.

48. Ribeiro, F.; Ferreira, P.; Araújo, M. Evaluating future scenarios for the power generation sector using a Multi-Criteria Decision Analysis (MCDA) tool: The Portuguese case. Energy 2013, 52, 126-136. [CrossRef]

49. Marzouk, M.; Amer, O.; El-said, M. Feasibility study of industrial projects using Simos' procedure. J. Civ. Eng. Manag. 2013, 19, 59-68. [CrossRef]

50. Ram, C.; Montibeller, G. Exploring the impact of evaluating strategic options in a scenario-based multi-criteria framework. Technol. Forecast. Soc. Chang. 2013, 80, 657-672. [CrossRef]

51. Stewart, T.J.; French, S.; Rios, J. Integrating multi-criteria decision analysis and scenario planning-Review and extension. Omega 2013, 41, 679-688. [CrossRef]

52. Chung, E.S.; Kim, Y. Development of fuzzy multi-criteria approach to prioritize locations of treated wastewater use considering climate change scenarios. J. Environ. Manag. 2014, 146, 505-516. [CrossRef] [PubMed]

53. Sawicka, H.; Zak, J. Ranking of distribution system's redesign scenarios using stochastic MCDM/A procedure. Procedia Soc. Behav. Sci. 2014, 111, 186-196.

54. Streimikiene, D.; Sliogeriene, J.; Turskis, Z. Multi-criteria analysis of electricity generation technologies in Lithuania. Renew. Energy 2016, 85, 148-156. [CrossRef]

55. Cavallaro, F. Fuzzy TOPSIS approach for assessing thermal-energy storage in concentrated solar power (CSP) systems. Appl. Energy 2009, 87, 496-503. [CrossRef]

56. Cavallaro, F.; Zavadskas, E.K.; Streimikiene, D. Concentrated solar power (CSP) hybridized systems. Ranking based on an intuitionistic fuzzy multi-criteria algorithm. J. Clean. Prod. 2018, 179, 407-416. [CrossRef] 
57. Hashemkhani Zolfani, S.; Maknoon, R.; Zavadskas, E.K. Multiple Attribute Decision Making (MADM) based scenarios. Int. J. Strateg. Prop. Manag. 2016, 20, 101-111. [CrossRef]

58. Hashemkhani Zolfani, S.; Maknoon, R.; Zavadskas, E.K. MADM and Futures Studies; A necessity. In Proceedings of the 9th International Scientific Conference "Business and Management 2016", Vilnius, Lithuania, 12-13 May 2016; pp. 1-7. [CrossRef]

59. Kuosa, T. Evolution of Futures Studies. Futures 2011, 43, 327-336. [CrossRef]

60. Voros, J. A generic foresight process framework. Foresight 2003, 5, 10-21. [CrossRef]

61. Miles, I.; Keenan, M. Overview of Methods Used in Foresight, a Note Prepared for the UNIDO Textbook on Foresight Methodologies. 2004. Available online: www.cgee.org.br/atividades/redirKori/290 (accessed on 20 June 2016).

62. Saritas, O. Systemic Foresight methodology. In Science, Technology and Innovation Policy for the Future: Potential and Limits of Foresight Studies; Meissner, D., Gokhberg, L., Sokolov, A., Eds.; Springer: Berlin/Heidelberg, Germany, 2013; pp. 83-117.

63. Heilbroner, R. Visions of the Future: The Distant Past, Yesterday, Today, Tomorrow; Oxford University Press and New York Public Library: New York, NY, USA, 1995.

64. Schwartz, P. The Art of the Long View: Planning for the Future in an Uncertain World; Richmond Ventures: North Sydney, Australia, 1996.

65. Glenn, J.C. Introduction to the Futures Research Methodology Series; AC/UNU Millennium Project; 1994.

66. Voros, J. Integral Futures: An approach to futures inquiry. Futures 2008, 40, 190-201. [CrossRef]

67. Wang, Q.; Dai, H.N.; Wang, H. A Smart MCDM Framework to Evaluate the Impact of Air Pollution on City Sustainability: A Case Study from China. Sustainability 2017, 9, 911. [CrossRef]

68. Wu, D.; Yang, Z.; Wang, N.; Li, C.; Yang, Y. An Integrated Multi-Criteria Decision Making Model and AHP Weighting Uncertainty Analysis for Sustainability Assessment of Coal-Fired Power Units. Sustainability 2018, 10, 1700. [CrossRef]

69. Zavadskas, E.K.; Antucheviciene, J.; Vilutiene, T.; Adeli, H. Sustainable Decision-Making in Civil Engineering, Construction and Building Technology. Sustainability 2018, 10, 14. [CrossRef]

70. Cavallaro, F.; Zavadskas, E.K.; Raslanas, S. Evaluation of Combined Heat and Power (CHP) Systems Using Fuzzy Shannon Entropy and Fuzzy TOPSIS. Sustainability 2016, 8, 556. [CrossRef]

71. Shen, K.Y.; Tzeng, G.H. Advances in Multiple Criteria Decision Making for Sustainability: Modeling and Applications. Sustainability 2018, 10, 1600. [CrossRef]

72. Lee, Z.Y.; Chu, M.T.; Chen, S.S.; Tsai, C.H. Identifying Comprehensive Key Criteria of Sustainable Development for Traditional Manufacturing in Taiwan. Sustainability 2018, 10, 3275. [CrossRef]

73. Tonn, B.E. Futures sustainability. Futures 2007, 39, 1097-1116. [CrossRef]

74. Dincer, I.; Rosen, M.A. EXERGY; Energy, Environment and Sustainable Development; Elsevier: Amsterdam, The Netherlands, 2007.

(C) 2018 by the authors. Licensee MDPI, Basel, Switzerland. This article is an open access article distributed under the terms and conditions of the Creative Commons Attribution (CC BY) license (http://creativecommons.org/licenses/by/4.0/). 